Original article

\title{
Ex vivo study of Cinnamomum zeylanicum Blume on antioxidative system and structural modifications of erythrocytes under hyperglycemic conditions
}

\author{
Vaibhavi Patel, Nupur Mehrotra and Sara Anees Khan \\ Department of Biochemistry, SVKM's Mithibai College of Arts, Chauhan Institute of Science \& Amrutben Jivanlal \\ College of Commerce and Economics (Autonomous), Vile-Parle (West), Mumbai-400056, India
}

Received October 30, 2019: Revised December 17, 2019: Accepted December 20, 2019: Published online December 30, 2019

\begin{abstract}
Hyperglycemic exposure, ex vivo of erythrocytes is often employed as a model for understanding membrane modifications in erythrocytes due to enhanced oxidative stress in diabetes. Chronic hyperglycemia leads to free radicals' generation along with an increase in insulin resistance. In the current study, the effect of Cinnamomum zeylanicum Blume, hydroacetone extract on oxidative stress and membranes of erythrocytes exposed to hyperglycemic conditions was investigated. Hemolysis as a measure of lipid peroxidation was studied by exposing erythrocytes to an increasing glucose concentration in presence and absence of the cinnamon extract.

In erythrocytes subjected to lower glucose concentrations, the percent hemolysis was higher. Higher glucose concentration attenuated hemolysis. Cinnamon extract supplementation reduced hemolysis by $91.20-50.10 \%$ in presence of 10-100 mM glucose, respectively. The results also illustrated that cinnamon extract supplementation significantly reduced oxidative stress induced-damage and enhanced activity of superoxide dismutase, evaluated by inhibition of pyrogallol auto-oxidation. It can, thus be hypothesized that cinnamon can prevent lipid peroxidation and enzyme glycation in human erythrocytes under diabetic condition.
\end{abstract}

Key words: Cinnamomum zeylanicum Blume, diabetes, oxidative stress, lipid peroxidation, hemolysis, superoxide dismutase

\section{Introduction}

According to a report published in 2017 by the International Diabetic Federation, 72 million cases of diabetes were reported from India, thus leading to India being referred to as the diabetic capital of the world. As per American Diabetes Association, diabetes is defined as a group of metabolic diseases, characterized by hyperglycemia arising due to defects in insulin secretion/action or both. A chronic illness, it requires patient self-management education, continuous monitoring and medical care, along with therapy to prevent acute complications and reduce the risk of long term complications (American Diabetes Association, 2010).

Diabetes enhances the risk of cardiovascular diseases as stroke, myocardial infarction, along with peripheral vascular diseases, like acute or chronic ischemia of leg leading to severe pain especially when walking short distances. Further, the risk of retinopathies, nephropathies, nerve damage and sexual dysfunction also increases.

\footnotetext{
Author for correspondence: Dr. Nupur Mehrotra

Assistant Professor, Department of Biochemistry, SVKM's Mithibai College of Arts, Chauhan Institute of Science \& Amrutben Jivanlal College of Commerce and Economics (Autonomous), Bhaktivedanta Swami Marg, Vile Parle (West), Mumbai-400056, India

E-mail: nupur.mehrotra@mithibai.ac.in

Tel.: +91-9833452122

Fax: +91-022-26130441
}

Copyright (C) 2019 Ukaaz Publications. All rights reserved.

Email: ukaaz@yahoo.com; Website: www.ukaazpublications.com
Better regulation of blood sugar is pivotal for reducing the risk of these complications (Leach and Kumar, 2012).

Oxidative stress leads to lipid peroxidation that in turn is associated with micro and macro-vascular complications associated with type 2 diabetes mellitus (Rehman and Akash, 2017).

Priyadarshini et al. (2015) reported that hyperglycemia leads to structural changes in red cell corpuscles due to osmotic stress. A detailed methodology to study hemolytic activity of palytoxin on human erythrocytes has been suggested by Malagoli (2007). A modification of this method was used in the present study to evaluate the hemolytic activity of glucose.

Studies by Franco et al. (2011) support the generation of oxidative stress under hyperglycemic conditions as the cause of complications, such as endothelial dysfunction in the blood vessels of diabetic patients. Increasing evidence from both experimental and clinical studies suggest that oxidative stress plays a major role in the pathogenesis of the two types of diabetes mellitus. Oxidative cellular stress results due to an imbalance between free radical generation and elimination (Valko et al., 2007). Also convincing experimental as well as clinical evidence suggests that the production of reactive oxygen species (ROS) viz-superoxide, hydroxyl radical and uncharged species such as hydrogen peroxide and singlet oxygen increases in diabetes type 1 as well as type 2 (Johansen et al., 2005). In diabetes, the possible source of free radicals may be due 
to auto-oxidation of glucose. A shift in redox balance is observed due to a reduction in tissue concentrations of natural antioxidants as reduced glutathione (GSH) or due to impaired activities of antioxidant enzymes such as superoxide dismutase (SOD) and catalase (CAT) (Haskins et al., 2003). Maritim et al. (2003), suggested that dis-proportionate formation of free radicals in diabetes may occur due to glucose oxidation, non-enzymatic glycation of proteins, and the subsequent oxidative degradation of glycated proteins, thus promoting development of complications associated with diabetes mellitus.

Numerous drugs are approved for the treatment of type 2 diabetes. These are largely based on relatively short-term efficacy in glycemic reduction, although their use is associated with multiple adverse effects. Traditionally plants in India have been known to possess various medicinal qualities that are attributed to their active principles. They are known to have a great variety of beneficiary activities like maintaining carbohydrate metabolism, restoring function and integrity of $\beta$ cells, insulin releasing activity and improving glucose uptake. Further, the antioxidant potential of these plants also offers immense opportunity to develop them into novel therapeutics (Singh et al., 2012).

Broadhurst et al. (2000) provided information on the use of more than 49 species of plants that possess antidiabetic activity. The protective potential of herbal hypoglycemic agents like Allium sativum, Azadirachta indica, Momordica charantia, and Ocimum sanctum on antioxidant status in streptozotocin-induced diabetic rats has been studied. These herbal remedies not only possess hypoglycemic properties, but also decrease the oxidative load in diabetes mellitus and the long-term use of such agents might help in the prevention of diabetes-associated complications. Chandra et al. (2013) reported the use of over 1200 plants as traditional remedies for diabetes, although only a few of them have been authenticated scientifically along with medical evaluation to assess their efficacy. Today, many formulations based on these herbal products are widely available in the market and are used regularly by diabetic patients, sometimes in preference to allopathic treatment (Modak et al., 2007).

C. zeylanicum as an antidiabetic and an antioxidant has attracted many researchers. Wariyapperuma et al. (2017) have determined the $\alpha$-amylase and $\alpha$-glucosidase inhibitory potential of the extract of cinnamon bark by pressured water extraction and solvent extraction. Short as well as long term effects of $C$. zeylanicum on food consumption, body weight, glycemic control and lipids in healthy and diabetes-induced rats was studied by Ranasinghe et al. (2012) and the results indicated that the spice lowered blood glucose, reduced food intake and improved lipid parameters in diabetesinduced rats. As per the study of Kim (2006a) cinnamon extract has been found to exhibit a regulatory role in maintaining blood glucose level and also improves insulin sensitivity by slowing absorption of carbohydrates in the small intestine.

Adisakwattana et al. (2011) evaluated intestinal $\alpha$-glucosidase (maltase and sucrase) and pancreatic $\alpha$-amylase inhibitory activity of four cinnamon sub-types (including C. zeylanicum) and its effect in combination with Acarbose. The study demonstrated that all four types of cinnamon inhibited maltase, sucrase and pancreatic $\alpha$-amylase, with Thai cinnamon (C. bejolghota) extract being the most potent inhibitor against the intestinal maltase. Routine flavouring of food with cinnamon spice can help the body to relieve oxidative stress and also fight microbial infections as the herb possess antioxidant and antibacterial activities (Mazimba et al., 2015). Peripheral blood erythrocytes and their membranes have been the entity of this study as they play an important role in various physiological and metabolic events. Protective effects of some phytochemicals have been studied by Pandey and Rizvi (2012), though studies investigating the protective effects of $C$. zeylanicum supplementation on human erythrocytes are limited.

In the present study, we postulate that cinnamon extract supplementation to erythrocytes can lead to decreased hemolysis. Also, depletion of antioxidant enzymes in hyperglycemic environment can be considerably reduced thus protecting the cell from osmotic fragility and subsequent lysis.

\section{Materials and Methods}

\subsection{Ethical committee approval}

The study was approved by the Institutional Ethical Committee (IEC)

\subsection{Crude extract preparation}

The bark of Cinnamomum zeylanicum Blume was sourced from Srilanka. The plant sample (Herbarium number: MIT0130) was authenticated by Department of Botany, Mithibai College (Autonomous). The bark cuttings were dried in a hot air oven at $40^{\circ} \mathrm{C}$ and blended into fine powder for extraction. The hydroacetone extract was prepared by mixing $0.2 \mathrm{~g}$ of spice powder with $5 \mathrm{ml}$ of $50 \%$ hydroacetone on a rotary shaker to enable complete extraction for $24 \mathrm{~h}$. The extracts were filtered and dried. The extract was reconstituted in DMSO and suitable dilutions of $160 \mu \mathrm{g} / \mathrm{ml}$ and $80 \mu \mathrm{g} / \mathrm{ml}$ were prepared for the assay. The yield of extract was $4.89 \pm 0.05 \%$.

\subsection{Qualitative phytochemical analysis}

Several phytochemicals present in C. zeylanicum attribute to its pharmaceutical properties. These have been qualitatively identified using modified method of Modi et al. (2018).

\subsection{Sample preparation and resuspension in buffer}

$3 \mathrm{ml}$ of animal blood was collected into EDTA vials. The whole blood was washed with chilled phosphate buffered saline followed by centrifugation at $2000 \mathrm{rpm}$ for $5 \mathrm{~min}$. The plasma and the buffy leukocyte layer were aspirated gently. The washing was repeated twice and the packed cells so obtained were used to make necessary suspensions of $2 \%$ for hemolysis study and $5 \%$ for SOD study.

\subsection{Hemolysis assay}

Exoerythrocytic hemoglobin obtained from the cell upon lysis due to hyperglycemic conditions was estimated by the modified method of Malagoli (2007).

Degree of hemolysis $(\%)=$ Ext $_{540}$ of sample $/$ Ext $_{540}$ of positive control * 100

\subsection{Erythrocyte superoxide dismutase activity}

Superoxide dismutase activity was estimated using a modification of Marklund and Marklund (1974) method. The inhibition of 
pyrogallol auto-oxidation brought about by superoxide dismutase from erythrocytes, over a period of 5 min was recorded.

\subsection{Statistical analysis}

The data were expressed as mean $\pm \mathrm{SE}$ for $\mathrm{n}=5$. Statistical analysis of the results was performed using Student's t-test. $p<0.05$ was considered to be statistically significant.

\section{Results}

\subsection{Qualitative phytochemical analysis}

In the current study, the plant extract was subjected to phytochemical screening, which showed the presence of free reducing sugars, tannins, sterols, terpenoids, flavonoids, phenols and coumarins (Table 1). These phytochemicals are best extracted in organic solvents and previous studies have used solvents as ethanol, methanol, chloroform, benzene and others for extract preparation, the toxicity of these solvent extracts, though is questioned (Nana et al., 2011). To minimize the toxicity of solvents, a combination of water and acetone, viz., $50 \%$ hydroacetone extract was used and since this solvent has not been used widely, the qualitative phytochemical analysis assisted in delineating the active components extracted in the solvent for the study.

Several phytochemicals present in C. zeylanicum attribute to its pharmaceutical properties. In this study, the hydroacetone extract was subjected to phytochemical screening whose results are presented in the following Table 1.

Table 1: Qualitative phytochemical analysis

\begin{tabular}{|l|l|l|}
\hline Test & Observation & Inference \\
\hline Molisch test for carbohydrates & Formation of a dull violet colour at the interface & Carbohydrates present \\
Barfoed's test for reducing sugars & Reddish precipitate of cuprous oxide absent & Monosaccharide's absent \\
Fehling's test for free reducing sugars & Reddish precipitate of cuprous oxide formed & Free reducing sugars present \\
Fehling test for combined reducing sugars & Reddish precipitate of cuprous oxide absent & Combined reducing sugars absent \\
Test for tannins & Appearance of brownish green colour & Tannins present \\
Liebermann-Burchard test for sterols & Formation of dark pink colour & Sterols present \\
Test for terpenoids & Formation reddish brown colour at the interface & Terpenoids present \\
Test for saponins & Foaming does not take place & Saponins absent \\
Ferric chloride test for flavonoids & Formation of blue green colour & Flavonoids present \\
Test for phenols & Deep blue colour formed & Phenols present \\
Mayer's test for alkaloids & No cream coloured precipitate obtained & Alkaloids absent \\
Hager's test for alkaloids & No prominent yellow precipitate formed & Alkaloids absent \\
Test for coumarins & Yellow colour formed & Coumarins present \\
\hline
\end{tabular}

\subsection{Hemolysis assay}

The shielding effect of cinnamon extract on red blood cells under oxidative stress, ex vivo, was estimated by colorimetric estimation of exoerythrocytic hemoglobin supplied by the cell in the medium upon lysis, when subjected to hyperglycemic conditions (Table 2, Figure 1). It was observed that in erythrocytes subjected to lower glucose concentrations $(10 \mathrm{mM})$, the percent hemolysis was high as compared to higher glucose concentration $(100 \mathrm{mM})$. On the other hand, cells pre-incubated with cinnamon extract exhibited hemolysis of $5.02 \%$ when glucose concentration in the suspension was $100 \mathrm{mM}$ and $6.312 \%$ when the glucose concentration in the suspension was $10 \mathrm{mM}$.

The percent increase in erythrocyte membrane stability in presence of cinnamon extract was $91.20 \%, 88.90 \%, 86.45 \% 80.47 \%, 62.60 \%$ and $50.10 \%$, respectively between $10-100 \mathrm{mM}$ glucose concentration in the suspension (Table 3, Figure 2). The same was calculated as:

$\%$ hemolysis with glucose - \% hemolysis with glucose and cinnamon extract

$\%$ hemolysis with glucose $\mathrm{x} 100$

Thus, cinnamon extract supplementation helped maintain the normal physiology of cell even under hyperglycemic environment. However, after $24 \mathrm{~h}$, cells with cinnamon extract supplementation also underwent eryptosis (cell death) in hyperglycemic conditions owing to osmotic fragility of the erythrocytes.
Table 2: Hemolysis assay: Percent hemolysis with increasing concentration of glucose alone and in presence of cinnamon extract, estimated by measuring extinction values at $540 \mathrm{~nm}$

\begin{tabular}{|c|c|c|}
\hline $\begin{array}{c}\text { Glucose } \\
\text { concentration } \\
\text { (m M) }\end{array}$ & $\begin{array}{c}\text { \% hemolysis of } 2 \% \\
\text { RBC's } \\
\text { with glucose }\end{array}$ & $\begin{array}{c}\text { \% hemolysis of } 2 \% \\
\text { RBC's with glucose } \\
\text { and } \text { C. zeylanicum }\end{array}$ \\
\hline $\mathbf{1 0}$ & $71.80 \pm 12.39 \%$ & $6.31 \pm 1.08 * \%$ \\
$\mathbf{2 0}$ & $57.15 \pm 12.57 \%$ & $6.31 \pm 1.08 * \%$ \\
$\mathbf{4 0}$ & $37.05 \pm 11.22 \%$ & $5.02 \pm 0.10 * \%$ \\
$\mathbf{6 0}$ & $25.72 \pm 6.29 \%$ & $5.02 \pm 0.10 * \%$ \\
$\mathbf{8 0}$ & $13.41 \pm 5.33 \%$ & $5.02 \pm 0.10 \%$ \\
$\mathbf{1 0 0}$ & $10.06 \pm 5.10 \%$ & $5.02 \pm 0.10 \%$ \\
\hline
\end{tabular}

Values depicted are mean \pm SE of the readings where $n=5$.

Mean values superscripted by $*$ are statistically significant at $p<0.05$.

Table 3: Percent increase in erythrocyte membrane stability in presence of C. zeylanicum

\begin{tabular}{|c|c|}
\hline $\begin{array}{c}\text { Glucose } \\
\text { concentration (mM) }\end{array}$ & $\begin{array}{c}\text { Percent increase in erythrocyte membrane } \\
\text { stability in presence of } \text { C. zeylanicum }\end{array}$ \\
\hline $\mathbf{1 0}$ & $91.20 \pm 1.53 \%$ \\
$\mathbf{2 0}$ & $88.90 \pm 1.21 \%$ \\
$\mathbf{4 0}$ & $86.45 \pm 0.96 \%$ \\
$\mathbf{6 0}$ & $80.47 \pm 0.53 \%$ \\
$\mathbf{8 0}$ & $62.60 \pm 0.34 \%$ \\
$\mathbf{1 0 0}$ & $50.10 \pm 0.41 \%$ \\
\hline
\end{tabular}

Values depicted are mean \pm SE of the readings where $n=5$. 


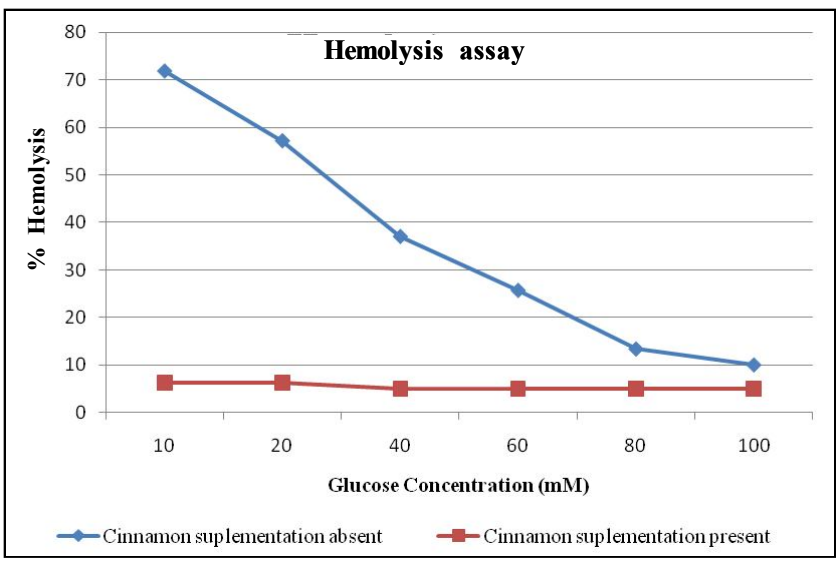

Figure 1: Hemolysis assay: Percent hemolysis with an increasing concentration of glucose alone and in presence of $C$. zeylanicum extract.

\subsection{Superoxide dismutase activity}

The inhibition of pyrogallol auto-oxidation brought about by superoxide dismutase is a useful tool in estimating enzyme activity. The results, thus obtained after addition of enzyme from the hemolysate of cells subjected to varied glucose concentrations show altered enzyme functions (Table 4, Figure 3). A significant loss in superoxide dismutase activity is observed in cells incubated with $100 \mathrm{mM}$ glucose as the values for percent inhibition of pyrogallo are negative $(-17.216 \%)$. This could result from conformational changes (possibly a glycation) occurring in the enzyme under hyperglycemic conditions. The negative value indicates that the

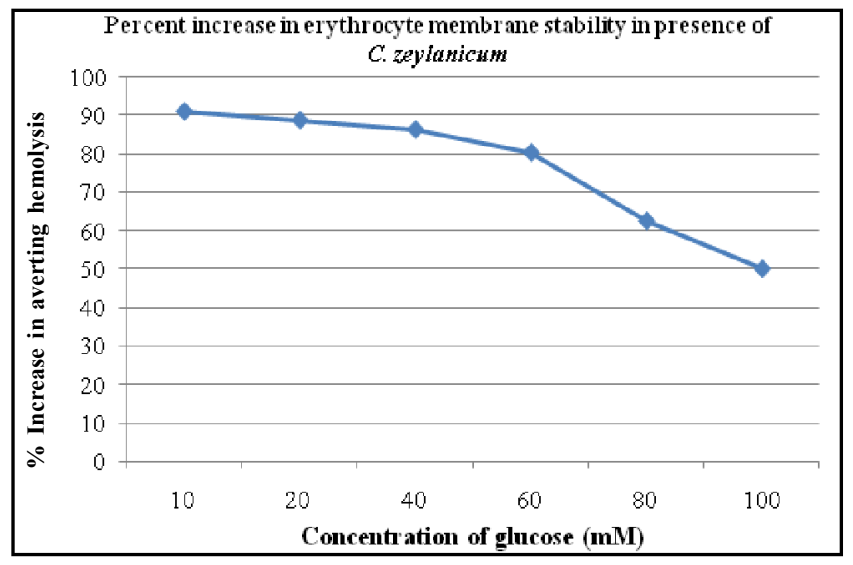

Values depicted are mean \pm SE of the readings where $n=5$

Figure 2: Percent increase in erythrocyte membrane stability in presence of C. zeylanicum.

enzyme is not capable of eliciting its function of scavenging superoxide radicals formed as a result of auto-oxidation of pyrogallol. However, the enzyme activity for inhibiting pyrogallol oxidation was enhanced when the cells were supplemented with $160 \mathrm{~g} / \mathrm{ml}$ and $80 \mathrm{~g} / \mathrm{ml}$ of cinnamon extract in the suspension. At both concentrations, cinnamon extract was effective in protecting the enzyme and maintaining its function. A higher inhibitory activity was observed when cells were incubated with $50 \mathrm{mM}$ glucose as compared to those incubated with $100 \mathrm{mM}$ glucose and supplemented with $160 \mathrm{~g} / \mathrm{ml}$ of cinnamon extract. The estimation of pyrogallol inhibition was performed at $329 \mathrm{~nm}$ in a UV-VIS spectrophotometer.

Table 4: Superoxide dismutase activity estimation through inhibition of pyrogallol auto-oxidation at $50 \mathrm{mM}$ and $100 \mathrm{mM}$ glucose concentration in presence of $80 \mathrm{~g} / \mathrm{ml}$ and $160 \mathrm{~g} / \mathrm{ml}$ C. zeylanicum extract

\begin{tabular}{|c|c|c|c|c|c|c|}
\hline Time (in minutes) & $\mathbf{t}_{\mathbf{0}}$ & $t_{1}$ & $\mathbf{t}_{2}$ & $\mathbf{t}_{3}$ & $\mathbf{t}_{4}$ & $\mathbf{t}_{5}$ \\
\hline \multicolumn{7}{|c|}{$\%$ Inhibition of pyrogallol } \\
\hline Glucose $100 \mathrm{mM}$ & $-17.22 \pm 10.70$ & $2.61 \pm 6.85$ & $5.81 \pm 4.64$ & $6.32 \pm 3.80$ & $10.34 \pm 4.47$ & $8.54 \pm 6.25$ \\
\hline Glucose 50 mM & $5.21 \pm 5.91$ & $11.99 \pm 3.49$ & $13.97 \pm 3.46$ & $11.48 \pm 3.81$ & $10.91 \pm 5.60$ & $7.88 \pm 8.28$ \\
\hline $\begin{array}{l}\text { C. zeylanicum extract } \\
160 \mathrm{~g} / \mathrm{ml} \text { in } 100 \mathrm{mM} \text { glucose }\end{array}$ & $40.65 \pm 11.44$ & $30.15 \pm 8.66^{*}$ & $27.46 \pm 7.37^{*}$ & $28.10 \pm 6.33^{*}$ & $33.02 \pm 6.06$ & $38.40 \pm 5.58^{*}$ \\
\hline $\begin{array}{l}\text { C. } \quad \text { zeylanicum extract } \\
160 \mathrm{~g} / \mathrm{ml} \text { in } 50 \mathrm{mM} \text { glucose }\end{array}$ & $50.48 \pm 7.80^{*}$ & $46.40 \pm 5.16^{*}$ & $38.12 \pm 3.62^{*}$ & $36.48 \pm 4.06^{*}$ & $40.18 \pm 5.12$ & $43.28 \pm 4.92^{*}$ \\
\hline $\begin{array}{l}\text { C. zeylanicum extract } \\
80 \mathrm{~g} / \mathrm{ml} \text { in } 100 \mathrm{mM} \text { glucose }\end{array}$ & $21.73 \pm 10.05^{*}$ & $24.43 \pm 9.11^{*}$ & $23.11 \pm 8.33^{*}$ & $22.62 \pm 7.67^{*}$ & $24.90 \pm 7.62^{*}$ & $27.86 \pm 8.20^{*}$ \\
\hline $\begin{array}{l}\text { C. zeylanicum extract } \\
80 \mathrm{~g} / \mathrm{ml} \text { in } 50 \mathrm{mM} \text { glucose }\end{array}$ & $25.91 \pm 12.97^{*}$ & $30.84 \pm 7.73^{*}$ & $26.70 \pm 6.81^{*}$ & $24.78 \pm 6.61^{*}$ & $27.63 \pm 7.50^{* *}$ & $28.32 \pm 8.40^{*}$ \\
\hline
\end{tabular}

Values depicted are mean \pm SE of the readings where $\mathrm{n}=5$.

Mean values superscripted by $*$ are statistically significant at $p<0.05$.

\section{Discussion}

The study aims to evaluate the therapeutic effect of $C$. zeylanicum as an alternative therapy for diabetes and it demonstrates that oxidative stress of human erythrocytes was attenuated in the presence of cinnamon in hyperglycemic conditions.

Higher glucose concentrations attenuated the rate of hemolysis in erythrocytes and the results are similar to that obtained by Viskupicova et al. (2015). An important aspect in this type of study is that cells incubated with initial concentrations of glucose utilize it during the course of incubation whereas at higher concentrations of glucose, a constant energy supply is maintained.

Kim et al. (2006b) suggested that derivatives of dihydroxyl-cinnamic acid in cinnamon, were found to increase glucose disposal by

enhancing translocation of GLUT4 transporters in streptozotocin induced diabetic rats. Phytochemical analysis of the hydroacetone extract under study suggests presence of phenols, and cinnamic acid is one such phenol. Sharma et al. (2018) suggested that such a mechanism can be utilized for preventing immediate blood sugar rise in diabetics and the results of current study correlates with these findings. However, the active component responsible for enhancing lipid peroxidation in membranes of erythrocytes is not yet understood.

Superoxide dismutase plays an essential role in reducing oxidative stress in the human body. In the current study, cinnamon supplementation maintained a higher enzyme activity than the control groups. Ookawara et al. (1992), suggested site specific and random fragmentation of $\mathrm{Cu}-\mathrm{Zn}$ SOD following glycation reaction 
while Kawamura et al. (1992), stated that glycated Cu-Zn SOD in patients with insulin dependent diabetes mellitus was $40.02 \%$ $(p<0.01)$. These studies indicate that glycated and less active $\mathrm{Cu}-$ $\mathrm{Zn}$ SOD are increased in erythrocytes of patients with insulindependent diabetes mellitus. Moreover, glycation, particularly of antioxidative enzymes, would enhance production of ROI, resulting in oxidative damage to the cells (Rahman et al., 2007).

Blood glucose is one of the main factors affecting glycated hemoglobin. Therefore, with an increase in blood glucose level an increase in non-enzymatic protein glycation between hemoglobin and blood glucose takes place, thereby increasing $\mathrm{HbA1c}$ level. On the other hand, hyperglycemia shortens the RBC lifespan, thus reducing the reaction time of glycation between hemoglobin and blood glucose (Huang et al., 2018).

Therefore, data from the present study supports the hypothesis that cinnamon extract prevents progressive glycation and excessive SOD exhaustion by high levels of glucose.

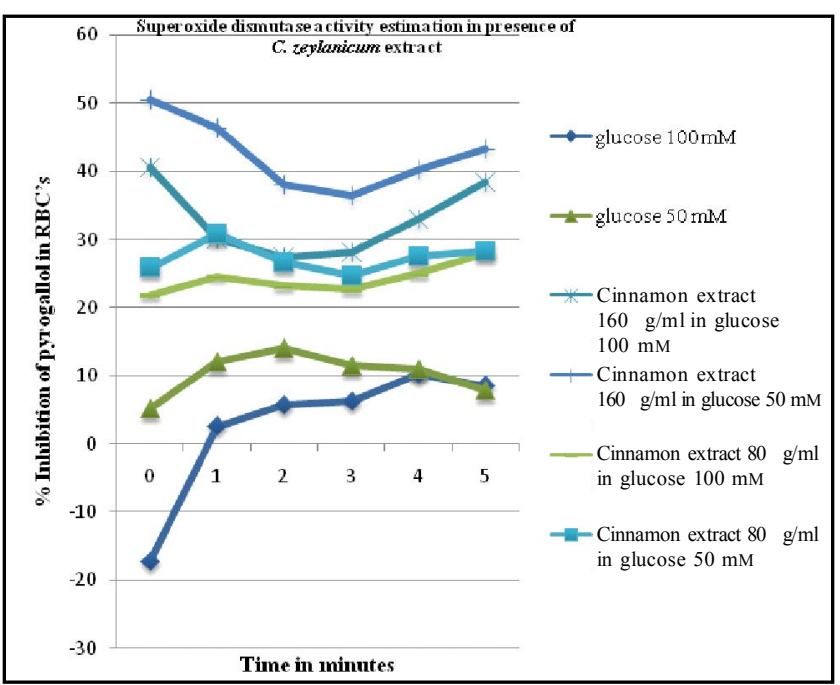

Figure 3: Superoxide dismutase activity

Values depicted are mean \pm SE of the readings where $n=5$

Superoxide dismutase activity estimation through inhibition of pyrogallol auto-oxidation at $50 \mathrm{mM}$ and $100 \mathrm{mM}$ glucose concentrations in presence of $80 \mathrm{~g} / \mathrm{ml}$ and $160 \mathrm{~g} / \mathrm{ml} \mathrm{C}$. zeylanicum extract.

\section{Conclusion}

The present study demonstrated that the extract of C. zeylanicum has the potential to be utilized as an antidiabetic as well as an antioxidative therapeutic agent. This study also revealed a remarkable reduction in lipid peroxidation through the hemolysis assay conducted. More importantly, the current study establishes that the antioxidant enzyme activity of superoxide dismutase is preserved by $C$. zeylanicum supplementation.

In conclusion, the results suggest that supplementation of the regular diet with cinnamon could benefit the antioxidant defence system, increasing the activity of antioxidant enzymes and alleviating lipid peroxidation of cell membranes at high glucose levels which is observed in case of diabetes mellitus.

\section{Acknowledgements}

Financial and infrastructural support to the department of Biochemistry from Shri Vile Parle Kelavani Mandal (SVKM) and a research grant (Research Project No. 78) from University of
Mumbai, BCUD-Minor Research Project to Dr. Sara Anees Khan is gratefully acknowledged. We acknowledge efforts of Dr. Bindu Gopalkrishnan, Department of Botany, Mithibai College (Autonomous) for authenticating the plant material.

\section{Conflict of interest}

The authors declare that there are no conflicts of interest in the course of conducting the research. All the authors had final decision regarding the manuscript and decision to submit the findings for publication.

\section{References}

Adisakwattana, S.; Lerdsuwankij, O.; Poputtachai, U.; Minipun, A. and Suparpprom, C. (2011). Inhibitory activity of cinnamon bark species and their combination effect with acarbose against intestinal $\alpha$ glucosidase and pancreatic $\alpha$-amylase. Plant Foods for Hum. Nutr., 66(2): $143-148$.

Broadhurst, C. L.; Polansk Marilyn, M. and Anderson Richard, A. (2000). Insulinlike biological activity of culinary and medicinal plant aqueous extracts in vitro. J. Agri. Food Chem., 48(3):849-852.

Chandra, A.; Sabharwal, R.; Chander, R.; Mahdi, F. and Mahdi, A.A. (2013). Effect of some indian herbs on dyslipidemia in streptozotocin induced diabetic rats. Int. J. Med. Dent. Sci., 2(1):24-33.

Franco, F.; Domenico, C.; Paolo, F.; Alberto, D.; Ana, P.; Andrea, G.; Carla, P. and Giovanna, M. (2011). The role of oxidative stress in the pathogenesis of type 2 diabetes mellitus micro-and macrovascular complications: avenues for a mechanistic-based therapeutic approach. Current Diabetes Rev., 7(5):313-324.

Haskins, K.; Bradley, B. and Powers, K. (2003). Oxidative stress in type 1 diabetes. Ann. N. Y. Acad. Sci., 1005:43-54.

Huang, Z.; Liu, Y.; Mao, Y.; Chen, W.; Xiao, Z. and Yu, Y. (2018). Relationship between glycated haemoglobin concentration and erythrocyte survival in type 2 diabetes mellitus determined by a modified carbon monoxide breath test. J. Breath Res., pp:12.

Johansen, J.S.; Harris, A.K.; Rychly, D.J. and Ergul, A. (2005). Oxidative stress and the use of antioxidants in diabetes: Linking basic science to clinical practice. Cardiovasc. Diabetol., 4:5.

Kawamura, N.; Ookawara, T.; Suzuki, K. and Konishi. K. (1992). Increased glycated $\mathrm{Cu}, \mathrm{Zn}$-superoxide dismutase levels in erythrocytes of patients with insulin-dependent Diabetes mellitus. J. Clin. Endocrin. Metab., 74(6):1352-1354.

Kim, W.; Khil, L.Y.; Clark, R.; Bok, S.H.; Kim, E.E.and Lee, S. (2006a). Naphthalene methyl ester derivative of dihydroxy hydrocinnamic acid, a component of cinnamon, increases glucose disposal by enhancing translocation of glucose transporter 4. Diabetologia, 49:2437-2448.

Kim, S.H.; Sun, H.H. and Se, Y.C. (2006b). Antidiabetic effect of cinnamon extract on blood glucose in $\mathrm{db} / \mathrm{db}$ mice. J. Ethnopharmacology, 104(1-2):119-123.

Leach, M. J. and Kumar, S. (2012). Cinnamon for diabetes mellitus. Cochrane systematic review: Intervention version published 12 th September.

Malagoli, D. (2007). A full-length protocol to test hemolytic activity of palytoxin on human erythrocytes. Invertebrate Sur. J., 4(2):92-94.

Maritim, A.C.; Sanders, R.A. and Watkins, J.B. (2003). 3rd. Diabetes, oxidative stress, and antioxidants: A review. J. Biochem. Mol. Toxicol., 17(1):24-38. 
Marklund, S. and Marklund, G. (1974). Involvement of the superoxide anion radical in the autoxidation of pyrogallol and a convenient assay for superoxide dismutase. Eur. J. Biochem., 47(3):469-474.

Mazimba, O.; Wale, K.; Tebogo, E.; Tebogo, E. and Kwape Shetonde, O. (2015). Cinnamomum verum: Ethylacetate and methanol extracts antioxidant and antimicrobial activity. J. Med. Plants Studies, 3(3):28-32.

Modak, M.; Dixit, P.; Londhe, J.; Ghaskadbi, S. and Devasagayam, T. P. A. (2007) Recent advances in Indian herbal drug research guest editor: Thomas Paul Asir Devasagayam Indian herbs and herbal drugs used for the treatment of diabetes. J. Clin. Biochem. Nutr., 40(3): $163-173$.

Modi M.C.; Ladumor C V.; Patel D.U.; Patel B.H.; Solanki L. S. and Bhadarka H.D. (2018). Phytochemical analysis and comparative study of in vitro free radical scavenging activity of different extracts of leaves of Abrus precatorius L. Ann. Phytomed., 7(2):133-137.

Nana H.M.; Ngane R.A.; Kuiate J.R.; Mogtomo L.M.; Tamokou J.D.; Ndifor F.; Mouokeu R.S.; Etame R.M.; Biyiti L. and Zollo P.H. (2011). Acute and subacute toxicity of the methanolic extract of Pteleopsis hylodendron stem bark. J. Ethnopharmacol., 137(1):70-76.

Ookawara, T.; Kawamura, N.; Kitagawa, Y. and Taniguchi, N. (1992). Sitespecific and random fragmentation of $\mathrm{Cu}, \mathrm{Zn}$ Superoxide dismutase by glycation reaction. Implication of reactive oxygen species. J. Biol. Chem., 267(26):185505-185510.

Pandey, K.B. and Rizvi, S. I. (2012). Protective effect of myricetin on osmotic stability of erythrocytes during aging in humans. Ann. Phytomed., 1(2):52-55.

Priyadarshini, H. K.; Latha, A. P.; Pradnya, S.; Juhi, A.; Samatha, P. and Mani Ratnam, K. (2015). Comparative study of erythrocyte fragility in diabetes mellitus and non diabetes mellitus. Int. J. Med. Res. Health Sci., 4(1):183-185.
Sharma, B.; Mittal, A. and Rajesh, D. (2018). Mechanistic approach of antidiabetic compounds identified from natural sources. Chem. Biol. Lett., 5(2):63-99.

Singh, K.R.; Pandey, K. B. and Rizvi, S. I. (2012). Medicinal properties of some Indian spices. Ann. Phytomed., 1(1):29-33.

Rahman, T.; Hosen, I.; Towhidul Islam, M. M. and Shekhar, H. U. (2017). Oxidative stress and human health. Adv. Bioscience Biotechnol., 3:997-1019.

Ranasinghe, P.; Perera, S.; Gunatilake, M.; Abeywardene, E.; Gunapala, N.; Premakumara, S.; Perera, K.; Lokuhetty, D. and Katulanda, P. (2012). Effects of Cinnamomum zeylanicum (Ceylon cinnamon) on blood glucose and lipids in a diabetic and healthy rat model. Pharmacognosy Res., 4(2):73-79.

Rehman, K. and Akash, M. S. (2017). Mechanism of generation of oxidative stress and pathophysiology of type 2 diabetes mellitus: How are they interlinked. J. Cell. Biochem., 118:3577-3585.

Valko, M.; Leibfritz, D.; Moncol. J.; Cronin, M.T.D.; Mazur, M. and Telser, J. (2007). Free radicals and antioxidants in normal physiological functions and human disease. Int. J. Biochem. Cell Biol., 39:44-84.

Viskupicova, J.; Blaskovic, D.; Galiniak, S.; Soszyński, M.; Bartosz, G.; Horakova, L. and Sadowska-Bartosz, I. (2015). Effect of high glucose concentrations on human erythrocytes in vitro. Red. Biol., 5:381-387.

Wariyapperuma, W.A. N. M.; Kannangara, S. D. P.; Wijayasinghe, Y. S.; Skandaraja, S. and Jayawardena, B. M. (2017). Pressured water extraction and solvent extraction of Cinnamomum zeylanicum (L.) bark and evaluation of antidiabetic properties. In: Proceedings of the International Postgraduate Research Conference 2017 (IPRC-2017), Faculty of Graduate Studies, University of Kelaniya, Sri Lanka.

Citation: Vaibhavi Patel, Nupur Mehrotra and Sara Anees Khan (2019). Ex vivo study of Cinnamomum zeylanicum Blume on antioxidative system and structural modifications of erythrocytes under hyperglycemic conditions. Ann. Phytomed., 8(2):150-155. 